\title{
EXPERIENCE ON PRENATAL GENTLE YOGA EXERCISE DURING PREGNANCY: A SCOPING REVIEW
}

\author{
Migita Vidia Amita, Sri Ratnaningsih
}

Faculty of Public Health, Universitas 'Aisyiyah Yogyakarta

\begin{abstract}
Background: The accelerated pace of physical and psychological changes during pregnancy can cause discomfort for pregnant women. Several studies claimed that maternal stress, depression, and anxiety level have a negative impact on birth outcomes. Yoga is a well-known exercise for emotional relaxation therapy. This study aimed to investigate the benefits of prenatal yoga exercise during pregnancy.

Subjects and Method: A scoping review method was conducted in eight stages including (1) Identification of study problems; (2) Determining priority problem and study question; (3) Determining framework; (4) Literature searching; (5) Article selection; (6) Critical appraisal; (7) Data extraction; and (8) Mapping. The search included Willey Online library, PubMed, and ScienceDirect databases. The inclusion criteria were English-language, full-text, and free access articles published between 2009 and 2019. The selected articles were appraised by Joanna Briggs Institute Critical Appraisal tools. The data were reported by the PRISMA flow chart.

Results: A total of 2,232 articles obtained from the search database, in which 2,093 articles were irrelevant, 95 duplicates, and 24 articles unmet inclusion criteria were excluded. Based on the selected 20 articles, eleven articles obtained A grade, and nine articles obtained B grade with quantitative (RCT, quasi-experiment, cross-sectional) and qualitative (focus group discussion) study designs. For main thematic findings reviewed were physical, psychological, labor process, and fetal benefits of prenatal gentle yoga exercise during pregnancy.

Conclusion: Prenatal gentle yoga exercise has benefits for both mother and fetus, especially the psychological well-being of mothers by reducing stress and anxiety. Active participation of husbands is required to enhance the effectiveness of prenatal yoga.
\end{abstract}

Keywords: prenatal gentle yoga, pregnancy, benefit

\section{Correspondence:}

Migita Vidia Amita. Faculty of Public Health, Universitas 'Aisyiyah Yogyakarta. Jl. Siliwangi (Ring Road Barat) No. 63 Mlangi, Nogotirto, Gamping, Sleman, Yogyakarta, 55292. Email: gitamigita16@gmail.com. Mobile: +6281466841970. 